\title{
Rootically invasive surgery: allow yourself and smile
}

\author{
Martin Riegler
}

Published online: 23 June 2020

(C) Springer-Verlag GmbH Austria, part of Springer Nature 2020

Dear readers,

welcome to this issue of European Surgery, which translates into a distinct spectrum of papers related to the full spectrum of general surgery. In addition, Mr. postman came and letters to the editor enrich this issue. Those letters are related to an infectious topic which has been fully addressed in the editorials published in the recent issues of European Surgery. Within these issues you would have heard about the relations between mythology and surgery, the metabolic cause of a disease, the interplay between major role and the inventions of man, which turned out to coin an episode of modern life and civilisation, which will be remembered as a very specific needle eye (Horus eye) experience. As thus major role interacted with the qualities of our modern social, economic and scientific world. Due to his great reputation, major role forced and still forces man to rethink and regather the way of life, attitude and mode of reasoning. First of all we have seen, that mythology and surgery reveal the same way of action. Both are manifestations of thought-induced modifications of quantum spacetime. Both, myth and surgery, work by a mechanism, involving the translation of images and pictures into treatable signs.

May you call it Shiva, Atman, Elohim, Brahman, man, Hamlet, woman, Dido, Anu, Baal, Amun, Aschera-Astarte, Artemis, Ister, Osiris, Quetzalcoatl, Viracocha, feathered snake, Isis, Venus, Mars, Neptun, Saturn, Zeus, collector (logos), satan, evil, beauty, thumb ears, embryo, blind eyes, cell culture, broken nose, adhesion molecule, twisted minds, molecular

Doz. Dr. M. Riegler $(\bowtie)$

Reflux \& Health Care, Mariannengasse 10/4/9, 1090 Wien, Austria

martin.riegler@refluxordination.at

structure, universe, big bang, Jahweh, Esther, brother, god, sister, Rastafari, father, mother, perception, INRI, John Lennon, Jesus, waiter, wailer, bunny, horse, treatise, method, brain wash, car wash, education, science, nature, shadows, sunlight, literature, music, composition, symphony, opera, wikipedia, google, love, your name, it all aims to translate the all in all in all into "all is one" in ALL (Fig. 1).

Depending on the site of discovery you name it pyramid texts, coffin texts, book of the dead, torah, bible, popol vuh, nature, science, European Surgery, The New England Journal of Medicine, Surgery, PUB MED. The term "all is one" in ALL codes, mirrors and echoes the idea of an omnipotent everlasting appearance. Disease drives symptoms. Symptoms lead you to the diagnosis. As such we aim to search for the "all is one" in all, and that gives us the hint what it is all about. The simple answer is: it is all about you. Thus this issue of European Surgery hopes and wishes to find your interest and wellbeing.

Now you may stop reading here and continue to enjoy the beautiful papers collected (logos) within this issue of the Journal. Maybe you may consider to return to those lines later. Question: may there be a considerable reason to do so, to return to those lines? Answer: maybe those lines carry thoughts and ideas that you might have questioned before in your individual existence, life and conduct of reasoning. Then you might find it somehow interesting and valuable to continue reading and searching for the I and I, the "all is one" in ALL. Please motivate yourself to say YES and let us proceed to utopia.

\section{Message for young surgeons}

Before we go to utopia we have to care for our young surgeons. Thus the following considerations are dedicated to those who carry the future of European 


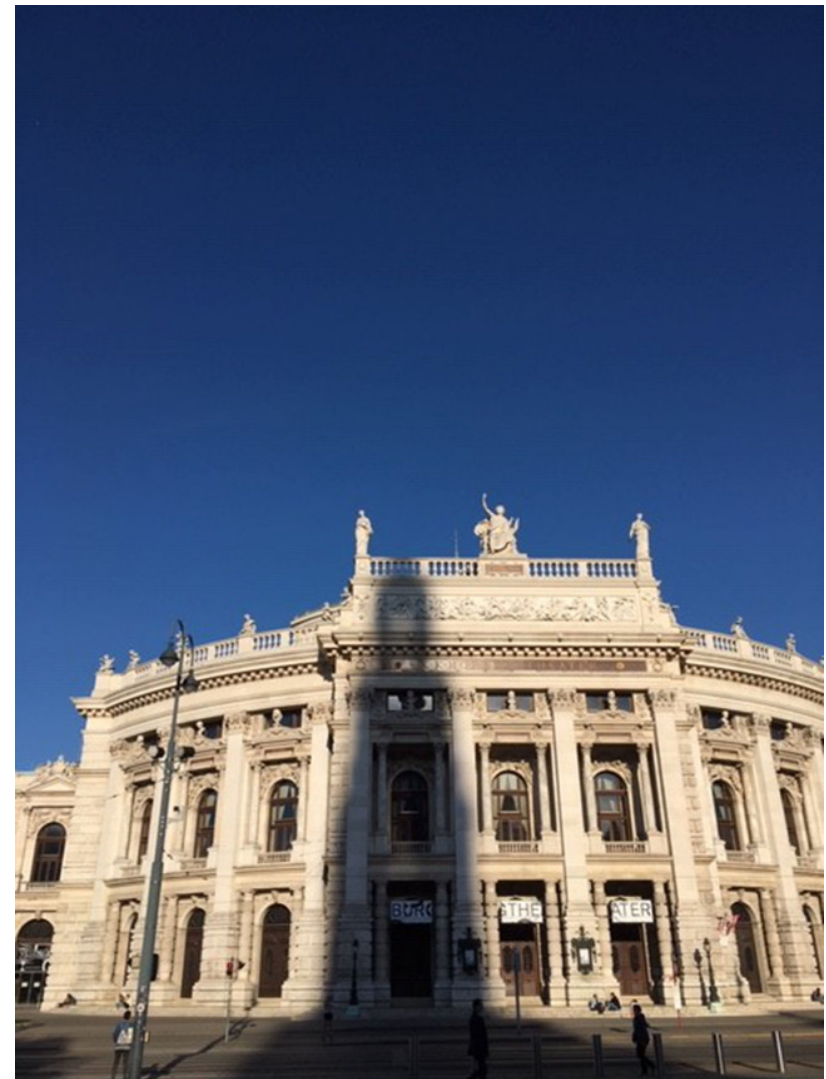

Fig. 1 The shadow of the Vienna town hall tower covers the facade of the Royal theatre Vienna and thus connects the evening sun with the earth and may serve as a tool for spacetime measurement. The image cartoons the idea of the author that all perceptions reflect the "all is one" in all. Optical biopsy obtained by the author, using attention

Surgery, those who are currently under training and education (T \& E): the young surgeons. Endlessly close to zero. This is the amount of knowledge a wise man is allowed to borrow during her or his life time from the universal quantum spacetime energy knowledge provided within our visible and invisible (black holes) universe, within our beautiful, fascinating cosmos. However, it is highly motivating to be allowed to borrow such small amount of knowledge. Why? It is the best we can get! Imagine your brain was the universe! It would have to explode and such an explosion would hurt a lot. Therefore, let us be happy enjoying the possibilities we have. And the story goes like this and is fully (100\%) dedicated to the young surgeons:

Conceptually surgery becomes art, if surgeons understand the mechanisms underlying the development of disease and the actions taking place behind the outbreak and flow of disease. Therefore, this is the message to the young surgeons (the message in the bottle!): young surgeons motivate yourself to search for the essence of your profession. Do not forget to accurately study anatomy, physiology and, most important, EMBRYOLOGY. Starting from there you will see, that almost all diseases that you treat derive and originate from nerve cells. Those nerve cells, that do not find room within the head compose the rest of the human body: nerve cells line the inner and outer surfaces (gut, bowels, intestines, lungs, bladders, thyroid gland, adrenals etc.; skin, breast, hair etc.). Conceptually all those cells are nerve cells. Those nerve cells are connected and supported by non-nerve cells, which originate from the bone marrow, connective tissue, bone, blood and lymphatic system. In addition to the transmission of information, nerve cells lining the inner and outer surfaces serve mechanical purposes and needs, too. Thus cells lining the gut and the skin serve the mediation of information and protect the body from environmental stress, infections, poisoning etc. For the transmission of information those cells are polarised and their cell membranes harbour a receiver and sending (transmitter) portion, which are separated from each other and from neighbouring nerve cells by the tight junction (TJ) complexes. Dear young surgeons: all cells lining the inner and outer surfaces are nerve cells connected and polarised by TJ complexes and represent manifestations of the quantum spacetime universe serving the translation and transmission of information. Our cosmos equals information, contains informations and represents a continuous biological process for the processing of information. Black holes do not deliver their information to us. Within this segmented pulsation of messages glands take their input from neighbouring nerve cells and transform this information into the release of hormones and transmitters which reach their effector tissues via the blood stream and other nerve cells. There those hormones act via the activation of receptors and cell membrane linked biochemical and molecular biological signal transduction pathways and cascades via the basolateral and/or apical cell membranes of our nerve cells. As such all surgery equals neurosurgery, i.e. cuts, dissects, resects, anastomoses, transplants, implants nerve cells, i.e. all surgery equals nerve cell surgery, including brain surgery, endocrine surgery, kidneys, liver and pancreatic surgery, ovary, breast, skin, eye, ears, tears, ENT, lung, oesophageal and gastric surgery etc. Thus you may understand, that you make your living by "playing" with nerve cells and why it is so important and essential to get the point: it is the "all in one" in all, nerve cell mediated orchestration of health and disease. The sooner you get to this point during your education, the better you are at your job.

If you cautiously collect the data from embryology you understand why the thyroid equals the sister of the submucosal gland of the oesophagus, why gastroesophageal reflux may induce and stimulate the development of thyroid nodes and foster struma-formation; you will understand why the eye and the oesophagus represent extrusions of the brain, why gut and gullet, oesophagus and anus belong to the same functional quantum spacetime phenomenon, why diseases of the inner surface (gut) may medi- 
ate the development of alterations and changes within the outer surface, i.e. the skin; why neuro-dermatitis, scleroderma, asthma, Hashimoto thyroiditis, inflammatory bowel disease, migraine, tinnitus, depression (affecting the nerve cells within the head) are essentially the same (ancestor reflux, stress and chocolate meet the point): these tissues open the source for the development of wellbeing and disease. Concentrated sugar containing food and beverages promotes the loss of TJ integrity. This in turn induces disarrangement of cell linings, apoptosis, dysplasia, dysfunction and loss of trans-epithelial electrical resistance in vitro and in vivo (i.e. diarrhoea, heartburn, asthma, migraine, tinnitus). As a consequence, nerve cells cease to function properly and metabolic disease, inflammation and cancer develop. As thus you now understand what it means to know embryology. Knowing embryology means to have an advantage. And this advantage translates into the possibility to perform a modern form of ancient medicine: prevention of disease.

Therefore, dear young surgeons: get yourself educated to be the health care manager of your patients. Prevent disease, apply the exciting modern technologies and techniques to assess the risk for disease development before the outbreak of such a disease impairs the life quality and the wellbeing of those affected. Understand that the genetical formatting explains the basis for the interplay between different parts of the human nerve cell systems ranging from the mouth to the anus, from the skin to the liver, from the eye to the lung. This understanding will help you to foster the wellbeing of your patients. Therefore: be the health care manager and prevent disease, maintain health and wellbeing. Be interdisciplinary and open your mind to look out of the small field of your speciality. This is your job for your future.

Today the generation of the author consists of a large group of well-educated specialists. Due to the immense and exclusive power of evidence based medicine, almost none of our generation adequately understands the holistic interplay and orchestration of the human body. We are all specialists. You can do different. Thus you may enrich yourself by putting it all together: be a great specialist, i.e. endocrine, liver, pancreatic, thyroid, bladder, skin, ENT, lung, oesophagus, stomach, belly, gut, hernia, kidney, vascular, transplant, plastic, oncologic surgeon, but allow yourself to orchestrate the holistic, big picture, large scale image of medicine. As such you will meet the requirements of future health care and medicine. Think positive and be part of the human myth. Even a drop of water held within the protection of the rose's leaf harbours the "all in one" in all (Fig. 2). Thanks for your attention, dear young surgeon.

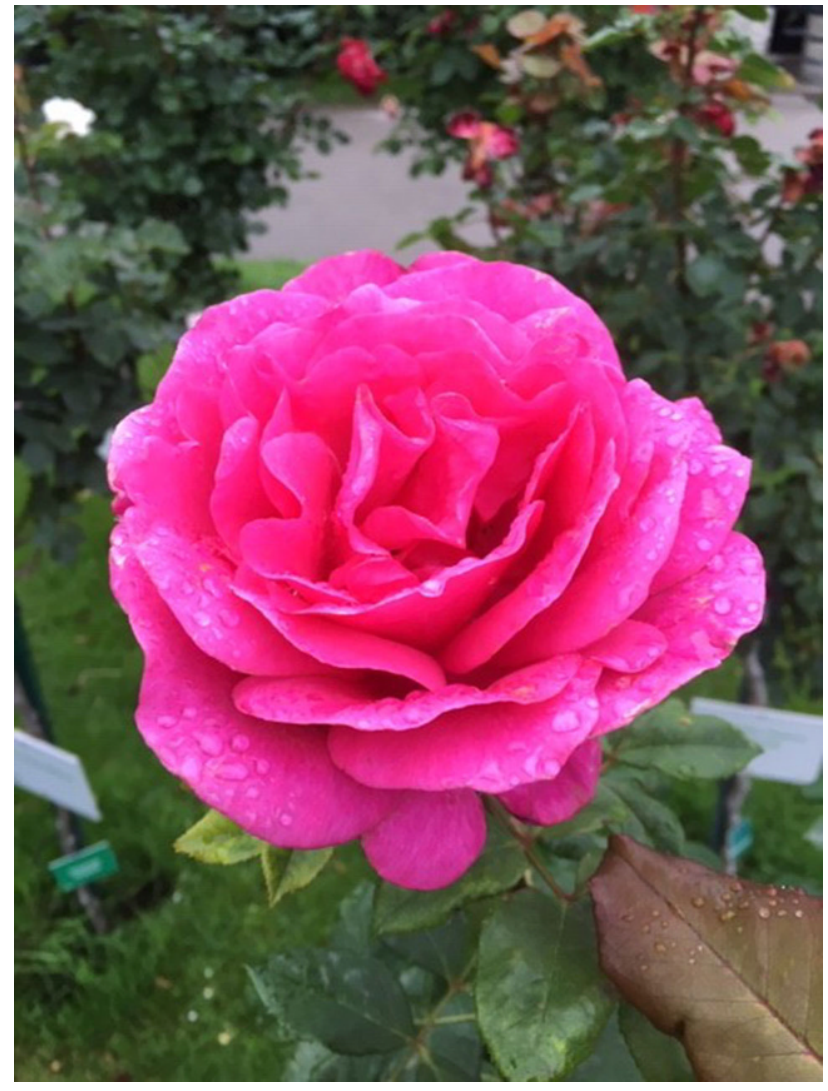

Fig. 2 The beauty of a rose after a short morning rain mirrors the idea of the author, that the world is beautiful and that all people were good if they had not been misled by various forms of despotic education. Optical biopsy obtained by the author, using attention

\section{Message for all surgeons:}

Here we go to utopia, "out of place", "out of usual mind", "out of group think" and may allow ourselves to resist all those qualities presented within our perceptions, which we basically do not like, favour, but are forced to support ("Sorry for futures on Fridays"). It happens and we have not been asked. It relates and does not care about us. It manifests without mattering essence-related qualities of reasoning and argument. Therefore, it is important to basically doubt it all and allow utopia to carry the mood, carry the theme, fusing the motives of our desires into the never ending atmosphere of our destiny, power and thought. Here we go. Jamaica, Negril, sunset, waves of the sea mingle with the sand of the beach, sitting and watching you may see the boats coming in, singing dreadlocks on top delivering a tension free mood: bongo man rhythm paces the sequential interruptions towards the beauty of the sound, wave watering dances and mingles from side to side and coconut tunings foster a smile. Coming out of the inner sense of the heart a secret unhides: we live, sing and foster for the beauty of our globe. Medicine unite! Treat the roots! We all share the same gut! And this very gut 
is connected to all galaxies out there in the universe. Therefore love coined utopia and utopia selected us. Let us proceed.

Try to take your TIME and try to enrich your SPACE. Please try to slowly read those lines, recognise your inner voice, listen to your inner voice, word by word, tune by tune, motive by motive, sentence by sentence. Take care of every word, watch out for every single meaning. Optimise your accurate attention and try to get the message of every single word. Listen to the "little notes". Step down and ask yourself: how are the qualities of my inner voice, is it male, female, the sound of a child, girl, boy? High, low, loud, silent? Ugly, cold, frustrating? Friendly? Catching? Devastating? Motivating? Positive? Electric? Mandatory? Valuable? Sounding? Emotional? Egocentric? How does the inner voice, reading those actual lines, relate to YOUR personality? Authentic? Artificial? Natural? Plastic smile? Then, as you have recognised your inner voice and you have got used to your inner voice, follow the instructions given in the text: start to read loud, when the text asks you to do so; reduce the volume and read silent, when the instructions within the text ask you to do so and so on. Follow the instructions. Follow the reading instructions. Listen to the sound. Follow your sound. Now YOU are the centre of the play. Now you are important, now you are within the focus of the interest, now you get the full attention. Did you ever receive full attention, except during the moments of your birth and death? We come within, in-between (inter faeces et urinam; in-between the hands of the gynaecologist; during a caesarian caesar salad ordered section) and go alone. Going in line with your private and business life: follow the instructions for the reader and do not hesitate to resist. As such you may echo the spacetime quanta of your room, office, praxis and sing: "I do not get no disinfection!" or "We don't need no disinfection", and simply go out to simply CLASH it upon the wall (cakes are simply made out of heathen). Enjoy yourself during listening to your own voice. At the end let your voice arise and get louder to orchestrate a very verbal symphony, a multi sonic harmony of sound. Multi-, oligo- and poly-semiotics count. Valuable and clever for ever. Please do not mind to involve the smell (i.e. the base line of our existence reggae!): the cloacas related to the interdisciplinary sound of hypocrite medicine, pharisee and pseudo-plagiarism stink around everywhere ("stinky reggae”). You are an exception, are you? Then, thereafter, as indicated, you may reduce the volume of your voice and get back to end within the beautiful awareness of harmonic silence, from where all has to start, begin and commence. Let us get silent and listen to the inner voice as it slowly reads the following lines:

The world is different. Your sound is different. Stupidity rules the world. Stupidity forms, makes up and composes the world. Humans are not important at all. Humans believe, that they (she or he) are important and may represent an exclusivity. Humans are guests allowed to stay on planet earth. Humans represent a vulnerable infectious disorder of planet earth. Humans force. Humans are the current pandemic of planet earth. You may sit in front of your PC or follow the lines on your tablet, cell phone or PC screen. Your inner voice continues to read: Around 66 mio. years ago another pandemic has been ended, terminated and eradicated by a gigantic cosmic impact (i.e. another cosmic infection!). The Holly Wood inventions involved within the stories around Jurassic park aim to recall and to remember the extinction of those 1000 to $10,000 \mathrm{~kg}$ heavy weight dino-trucks, which, at that time, "ruled", "crossed", "detected" the world. Due to their extinction mammals were allowed to prosper and foster their opportunities. Imagine (John Lennon) other animals await the extinction of man to foster and prosper! Following a little pause, which may allow the drink of a cup of coffee, (green) tea or water you may continue to read. Our eyes are those of Horus. The Horus eye models the gloom of the moon. Whenever I see the moon I recall the educational poem of Parmenides. Beautiful! Bright! Twisted! Whenever I watch the gloom of the moon I am aware, that the moon has already been there when the dinos walked, flew, swam around the archaic woods, lakes, green lands, shores of the Thetis ocean, that the eye of Horus might have been excited about what it has been allowed to see: during the nights the Horus eye might have seen the endless sized mirrors reflecting its own face and eye, the I. And the dinos also inhabited the lakes, the seas, the oceans of our planet. Of course, at that times the planet has not been ours, even today the planet is not ours, we have borrowed living time here, we are the guests, we borrowed episodes for our existence (met 4 life). Furthermore (this term is usually used to connect sentences within a scientific paper submitted for publication in the New England Journal of Medicine, Nature, Science, European Surgery, The World Journal of Surgery, Surgical Endoscopy, Economy etc.); furthermore, the mirror image of the "moon face" and I is and has been interrupted by black islands and moving dancers in the skies. Many million years later man came around to name them: ocean, continent, clouds. At a given point, man started to pray to the moon, stars and the milky way. Man started to cartoon the netherworld. And the woods of the Dinos have transformed into oil and gas. Three million years women and men ran around without knowing about oil and gas, without knowing, what oil and gas could have been used for. Suddenly invention happened, detection happened. And today this oil and this gas has been transformed into warfare, money and despotism. The use of these manifestations has been detected and invented by man and now drives the inventions and attitudes of man. Here I (Horus) see: the still image world does not exist, the world appears as a process and the world is beautiful (Fig. 2). 
Conceptually every child is good, and then starts this despotic process of education. As a consequence, children are transformed into machines to make money, into greedy machines to increase the power of those, who are in charge. I know that victims and love exist and that love drives the process which translates into the perception termed "existence", "being”. I know that love motivates positive changes and outstanding innovations. I am a surgeon. I wish to understand, what I am doing. I am a surgeon. I wish to know, I wish to discover: what is it all about? I am a surgeon, I wish to learn (€: this logo, this symbol is well taken and understood everywhere on this planet, imagine what happened if the same was true for love, peace, respect, tolerance, truth?). I am a surgeon, I love what I am allowed to do. I love my surgeries. I respect those, with whom I am allowed (and not forced) to perform surgeries. I am a teacher. Therefore, at least for this moment (what is now? what means now?), I allow myself to consider: we are utopia, we are brothers and sisters, living in peace and harmony, under many suns, under many skies, below many stars, moons and milky ways, netherworlds, below many changes of atmosphere.

All perceptions originate out of $\mathbf{m y}$, individual, personal stream of emotion, out of the inner circle of my heart, out of the inner circle of my desire, out of the inner circle of my Horus eye. I am the centre of my universe and as such I cannot imagine any other perception, except my own perception within this very, actual moment of emotion, temper, mood and atmosphere. (Even the lines within this text are YOUR perceptions, dear reader). European Surgery connects authors, readers and the industry. I cannot place myself out of my own perception. Impossible! I am a process and this particular process is named, ends, desires and hopes: the robot surgeon. Here you sit down on a chair and start to read using your outer language, so that you and your amigos can hear it, please speak at very low volume, quiet, distinct, slowly, word by word. It makes no sense to hurry, it makes no sense to combat with others. We all want to have the same: peace, love, happiness, cosiness, protection, respect and understanding. Please read louder and very slowly, word by word. It is, it is important, it is important to allow respect. It is essential, because it is essential and therefore translates into the essence to allow tolerance. I am great if I do, what I love. If I am great at what I am doing, money will also come along. Get louder by slowly reading word by word. Motivate others to laugh. Motivate others to be excited. Motivate others to discover, elucidate and detect. Motivate others for fun, joy and happiness. Motivate others to enrich the positivity of our planet. Here you have to get louder. Motivate others to think positive. Please read at the loudest volume that you are capable of. Motivate others to abandon hate, envy and greed. Motivate others to abandon pollution of matter and mind. Motivate silence. Listen to your breath, listen to your

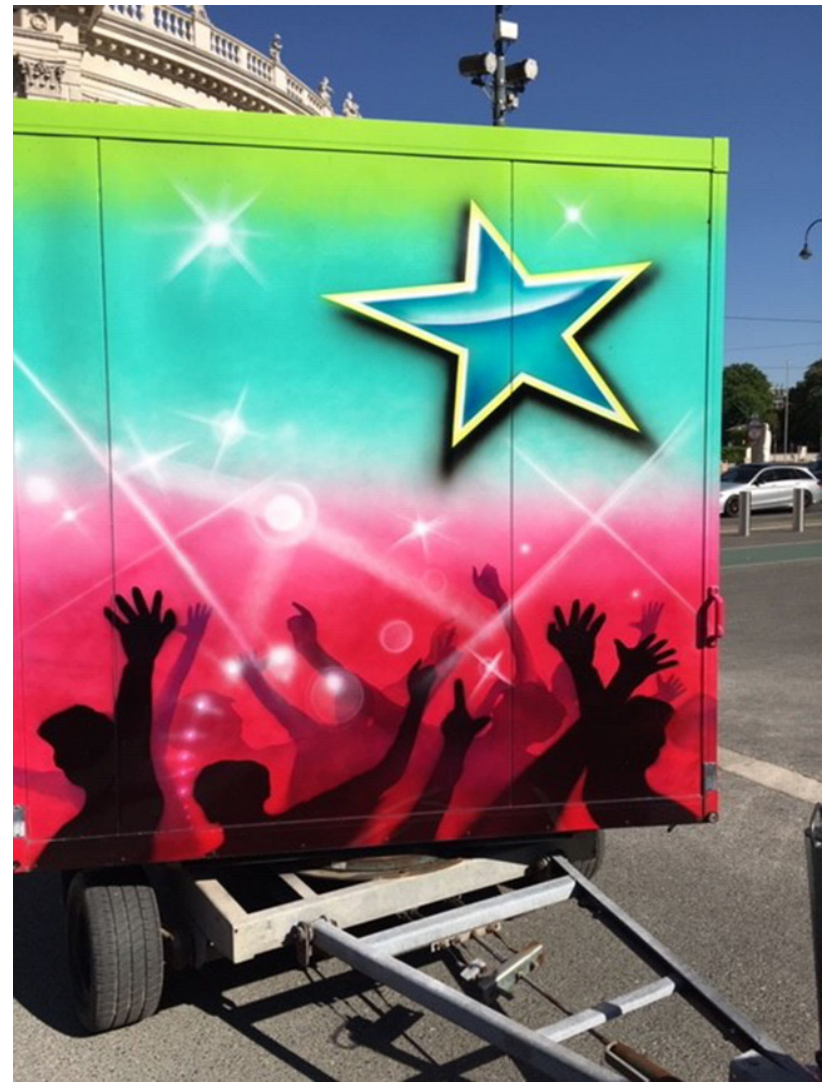

Fig. 3 This image aims to cartoon the idea of the author, that we are a great, beautiful show and that we are important, as long as we live humility. Optical biopsy obtained by the author, using attention

heart beat. Listen to the sound of your gut, gullet and stomach. Allow a pause. Allow an other pause. Stand up, raise your buttock and shout out loud. I stop to live the modes, models and desires of others. I want to gather with those who wish to escape the group think and ask: what is the nature of man? Here you sit down and continue with normal conversation volume, as if you were in the operation theatre and were kindly asking the nurse for an other forceps. Please, my dear, could you please tell me: what is the nature of man? What is nature? Where could we find nature? I mean, the stomach may be nature, but it has been turned into an artificial organ due to the consumption of plastic food and beverages. What is nature? The spine? Well, it has been changed into an artificial column due to the plastic way of motion, walk and sit. What is nature? The heart became an artificial muscle due to the intake and consumption of plastic medications, foods and beverages. What is nature? It may turn out that it all translates into artificial manifestations due to the great inventions of man. Here please stand up and shout out very slowly, word by word and very loud. It is all made up of human inventions, and these human inventions crush man to death. It is all made up of human inventions, and man translates INTO THE SLAVE OF HIS OWN INVENTIONS. Sit 
down and allow yourself a pause. Then continue word by word, slowly, but silent. We definitely became the slaves of our inventions. Let us name our inventions: all forms of logos, art, religion, warfare, politics (how to order, gather, manipulate and control people), philosophy (truth equals to that, what helps to increase power?), science (what justifies to gain more power and money?), economy (money justifies it all!!!). Let me try to live my utopia. Let me try to step out of my routine life. Let me allow to be different. Being is different. At least for some short moments may I be allowed to be different, so be a free time rasta, free time coconut Montegobay, Ochos Rios, Negril: guess who is coming to dinner? Smile Jamaica! Smile! And during these moments I may question my existence, I may question the qualities of my life. I may motivate myself to search for the "all is one" in All. That would definitely lead to the creation of the great smile. That would be awesome, delight, bliss upon bliss. Stand up and shout out very very loud. Bliss upon bliss! European Surgery! World Surgery! No more races, borders, enemies, walls!!! All is one!! All is one!! All translates into one (Heraclitus)! European Surgery connects people for peace, balance and respect, tolerance and understanding. Sit down again and continue slow motion, word by word, normal volume of your speech. From here our continuous stream of emotion fuses with the universal language of our existence, our being: to gar auto noein estin, te kai einai, thinking and being is the same (Parmenides). Beyond that starts essence based surgery, essence based medicine, rootically invasive surgery (RIS). Smile! We are roots, robots and reggae, we are Europe, we are the world, we are the universe. As long as we live humility, we are important and we are a great, beautiful show (Fig. 3). Stay tuned and let us enjoy this volume of European Surgery, be YOU,sincerely,

\section{Martin Riegler}

Acknowledgements The author thanks his family, friends, teachers, patients, Springer, the industry and curiosity for supporting his search for the "all is one" in All.

Conflict of interest M. Riegler declares that he has no competing interests.

Publisher's Note Springer Nature remains neutral with regard to jurisdictional claims in published maps and institutional affiliations. 